\title{
Understanding the Social Experience of Education from Adult Learners in South Australian Rural Communities
}

\author{
Jillian Marchant \\ Pauline Taylor
}

James Cook University

etropic 14.1 (2015): 64-71. http://www.reefandleaf.com.au/etropic.html \& http://www.jcu.edu.au/etropic

\begin{abstract}
This article offers a preliminary overview of a study that investigates the experiences of adult learners residing in rural communities in the state of South Australia. Online delivery of adult education is growing, allowing more individuals who are remote from learning sites to engage with further education. Increased educational opportunity to participate in learning as well as social policy developments with an emphasis on continuing education offers a chance in research to understand the developments generated by adult education. The work presented here shows a way of investigating social engagement offered through education, especially those that allow rural students to enhance their chances across the life course. It does so through engaging with the reports from adult students. Understanding the role of education through the social experiences of adult students in rural communities highlights the role of education in the areas of personal, social and community development.
\end{abstract}

Keywords: Adult Education; Rural Community; Social Engagement

\section{Introduction}

As a long-term resident in the rural areas of Australia, I have had many opportunities to experience and observe local social interactions. As an adult learner living in a rural area, I am also increasingly fascinated with the role of education to influence the social outcomes of rural communities and their members. Social outcomes may include the impact of education on the chances of adult learners or changes in their social influence within groups. Presently, a combination of ongoing environmental and economic stresses within regions reliant on primary production is detrimental to their social arrangements.

Particularly, diminishing resources and economic opportunities within some rural areas has led to the outmigration of many former residents into metropolitan locations (Smailes, 1995). Smailes (1995) work is a beginning in reviewing elements that may lead to social sustainability in the face of deteriorating rural communities. Among other issues, social dilution in communities or diminishing numbers of inhabitants is observed in research as an impediment to revitalising the social institutions that sustain communities and their inhabitants. Education, and particularly the "Skills for All" program, offers a way to revitalise the social and economic elements of South Australia. Previously, The South 
Australian Social Inclusion Initiative and the National Social Inclusion Agenda both proposed education as a means to generate social inclusion (Australian Social Inclusion Board, 2008b; Newman, Biedrzycki, Patterson, \& Baum, 2007). Social inclusion in policy documents is defined as the resources and capabilities to secure a job, access services, connect with other, deal with personal crises and being heard (Australian Social Inclusion Board, 2008b). Encouraging individuals to become "socially included" has become the driving force in Australian social policy to overcome social disadvantage both between regions and among individuals (Australian Social Inclusion Board, 2008a). Opportunities for individuals to achieve social inclusion through education are evidence in the "Skills for All” program. The program funds courses for South Australian residents who wish to undertake education and training for vocations where there are current skill shortages (Government of South Australia, 2012b). "Skills for All” offers a chance for individuals within South Australia to freely access education (Government of South Australia, 2012a). It is of interest for research to review the developments for individuals engaged with this formalised learning, especially as there is scant literature on the topic. Given the growing complexities and existing challenges in rural communities it is vital to understand if this type of formalised learning assists rural futures. Education processes of interest in this study may include personal or social benefits such as individuals gaining knowledge or self-understanding and sharing new information with other individuals. As education may form a large part in supporting the social aspects of rural futures, I am investigating the social experiences of adult learners that reside in the rural communities of South Australia. I anticipate that exploring these experiences will reveal the elements in adult education that assist both individuals and their communities.

\section{Understanding Social Arrangements in Rural Communities}

Social interactions and mechanisms in various rural regions of Australia often seem astoundingly similar. Previous research on rural areas in overseas locations finds that rural is a social system rather than a geographical area (Ashwood, 2010). Ashwood (2010) explains that rural becomes a dynamic social expression rather than a fixed category. Within Australia, the social expression of "rural" is generated through a combination of sparse populations in geographically isolated communities. Research in South Australia by Smailes (2002) explains that social arrangements in the rural areas of South Australia are marked by a heightened number of social interactions among members to inform decisions and initiate actions The greater number of social interactions among the residents in a community supplies assistance to individuals to survive the trials of everyday living. George Otero (2012) argues that this social mechanism in rural communities is an advantage, as rural inhabitants intuitively understand the significance and prioritise their social exchanges to ensure survival. In contradiction to this stance, Gray and Lawrence (2001) report that many rural communities are currently suffering social deterioration and experiencing crisis. Research that has examined the existing social arrangements in rural communities suggests that there are at least two possible contributors to their demise. First, the strong social bonds among individuals in rural areas that are formed through dense social interactions are sustained at the expense of members forming associations with individuals who are considered to be outside of the community (Onyx \& Bullen, 2000). These interactions with outsiders or dissimilar others is argued to be a source of innovative ideas that assist communities to meet existing challenges and forge development, without which community progress stalls. The second explanation surrounds the present challenges in rural communities, which includes the concurrent rise of globalisation and neoliberalism. Pritchard (2005) states that neoliberalism is a foundational 
transaction method for globalised markets and has become a foundation principle in the domestic policies that affect rural Australia. Market forces guiding the allocation of public goods and services have replaced compensatory mechanisms that were previously in place for rural communities (Pritchard, 2005). Many former rural inhabitants have therefore relocated to better-resourced metropolitan areas, signalling the social demise of rural communities (Alston, 2004).

\section{Social Inclusion Agenda and Education}

Australian policymakers have acknowledged that recent increases in disparity between regions and among individuals require urgent address to maintain social cohesion and a sense of togetherness that is at the foundation of societal arrangements (Vinson, 2009). The identification of individuals whose inequitable circumstances leads to their social exclusion from the benefits and influence that is enjoyed by a majority of Australians has led to the adoption of a Social Inclusion Agenda, anticipated to curb growing disparities (Australian Social Inclusion Board, 2011). Social Inclusion, as a means to curb growing inequity, is a method that was adopted into South Australian policy from its origins in Europe (Lenoir, 1974). Literature from the National and South Australian Social Inclusion Initiatives highlights the need for individuals to devise their own inclusion through being engaged with education or employment (Australian Social Inclusion Board, 2008a). An emphasis on social inclusion through employment and education has led to the South Australian Government initiated the "Skills for All” Program in 2011 (Government of South Australia, 2012b). This program funds education programs for employment where there are skill shortages, or are without enough employees to meet the demands of the economy.

The chance to understand the experiences of individuals engaged with education in a time that emphasises engagement, particularly for vocational purposes, is especially important. To investigate the reports of adult learners about their experiences allows understandings on the capacity of education to enhance the purported goal of social inclusion as well other personal and social benefits associated with formal learning. The evaluation of the influence of education on the social experiences of individuals will provide insights into the strengths and challenges of "Skills for All" and further knowledge about the beneficial social experiences that are facilitated by education. As adults living in the rural communities of South Australia have both unprecedented access to education and potentially experience marginalisation as community members and inhabitants in rural areas, their social experiences are of particular interest. Given that social inclusion is defined in policy as resources and capabilities, it is useful to understand the processes in education that build the resources and capabilities of the individual. As many rural communities are significantly marginalised from Australian society, it is pertinent to understanding the facilitators of social inclusion experiences for individuals. Having appreciated the processes that build resources and capabilities alongside the facilitators of social inclusion experiences it is highly relevant to examine the role of education in these circumstances. This study addresses the following research questions:

1. How is social inclusion offered through social interactions?

2. How are inclusive social experiences of adult learners facilitated inside and/or outside of their communities?

3. How does the experience of education influence these social experiences? 
The aim of this research is to gain an understanding of a range of social engagements that are influenced by individuals undertaking adult education. Adult education may comprise of a range of education courses that are available in rural communities, from a Certificate I to a Philosophy Doctorate. "Skills for All" funding covers endeavours that include Certificate I to an Advanced Diploma level. This research is significant as understanding the social engagement that arises from adult education may contribute to honing policy and process for adult learners in rural communities.

\section{Methodology}

The methodology used in the study was challenging to formulate. Where there is marginalisation it is possible for research to generate even greater marginalisation (Strega, 2005). Given this precaution and the complexity of social inclusion, I have used a case study approach to explore the experience of adult learners engaged in the "Skills for All" program. Contemporary social phenomena are not easily defined, and a case study approach leads itself to investigating social mechanisms in an explanatory manner (Yin, 2009). I conduct semi-structured interviews so that adult learners may reflect on their social experiences and to elicit those activities that have improved their life chances. After receiving an ethics approval from JCU, I used four approaches to enlist contributors. I contacted other rural students known to me, I advertised in a state-based newspaper. I used social media such as Facebook and a blog and; TAFE SA assisted me by emailing an invitation to regional students on my behalf. These techniques have been successful with 17 interviews completed, transcribed and approved by the contributors to be used in the study. Furthermore, the contributors to this study are located in a range of locations across the state. Using an inductive approach, I have begun to code the interviews in NVivo to understand the social experiences of the contributors in relation to the contributors. At the time of writing, the study has attracted a number of contributors that exceeds my expectations.

\section{Analysis}

The possibilities for analysis of the data from the interviews are discussed in three separate sections. First, are the findings about the social interactions that generate social inclusion; second, the location of that social experience as either within or outside of the contributors community and; last, the experience of education in influencing the social processes of adult learners.

\section{Findings: Social Inclusion}

Once of the most important aspects of the study is to understand the experience of social inclusion from the reports of the contributors and particularly the social interactions that generate that inclusion. Interestingly, contributors are able to identify both a state and a process of social inclusion. The state of being socially included for the contributors is an intriguing social arrangement that is dynamic and context specific. Succinctly, the definition of being "socially included" by the contributors is different to that defined by social policy documents. Particularly, contributors viewed social inclusion as a state whereby they could work in a group to contribute to the wellbeing of others. Contributors are able to identify the social elements and mechanisms that lead to an experience of being socially included. It is also apparent that adult learners as members of rural communities conceptualised what it means to be included and the social activities and outcomes that are 
most likely to generate an experience of being socially included. Contributors were also able to report on scenarios where being socially included was a restrictive rather than beneficial social experience. Among the reports about being "socially included" were comments that outlined the process as somewhat stifling, as the groups that contributors were included in may be opposed to new directions. This reported experience is an unexpected detrimental result that demonstrates that improving social inclusion does not necessarily lead to improving the chances of the individual or their community. There are also reported instances in the interviews whereby the social experiences of some contributors have been an outcome of exclusion. Social exclusion is often generated by groups in rural communities through frequent social activities that generate greater bonds among local individuals at the expense of excluding anyone who is considered to be an outsider. This finding aligns with the work of Onyx and Bullen (2000) who found that connections with outsiders or dissimilar others in rural communities is weaker than the internal social bonds. Whilst it is not the purpose of this research to explore social exclusion at length, it is nonetheless worthwhile to acknowledge that there are significant social mechanisms at work in rural communities that effectively exclude others. Understanding social inclusion through the social interactions of the contributors as adult learners residing in rural communities offers an appreciation of the experiences that constitute social inclusion and occasions where social inclusion can either further or diminish the chances of individuals.

\section{Findings: Within and Outside Community}

This section discusses the conditions that facilitate inclusive social experiences both within and outside of community as defined by the contributors. Contributors reported that social experiences that included them in their communities were most likely to occur through invitation from other members known to the contributor. Another important aspect was for contributors to define what community is for them, allowing me to review their reported social activities in terms of being located inside or external to their community. According to the varied perspectives of contributors, community may be defined by geography, or by shared interest. It appeared that contributors often enlarged their geographical community to include a nearby town where they worked or engaged in regular social activity Where the geographic boundaries were not applicable, the conception of community was expanded to include a common philosophical orientation. This description was essential to give meaning to a place where contributors connected with others in a way that was important to them.

Despite a sense of connection to several communities, contributors reported a lack of consultation on the decisions that affect them the most both within and outside of community. Contributors did not express an expectation that they would or should be involved in choices that affected their future. Many reported that the voice of their elected representatives was disregarded in decision-making structures that are often metrocentric, or based in metropolitan areas for the benefit of metropolitan members. Examining the conditions for inclusion both within and outside of contributors' communities reveals information about the inclusion of adult learners both within their community, and potentially as representatives of their communities. The evidence reflects poorly on the possibilities for the residents of rural communities to be socially included. 


\section{Findings: Adult Learners' Social Experience}

Contributors discussed their social experiences as adult learners both within and outside of their identified communities. These social experiences were discussed in terms of being either beneficial or restrictive in furthering their life goals. Contributors glowingly cited the personal development benefits of their education. However, many contributors mentioned that their education experience was often socially restrictive as they juggled precious time resources to complete their education course. Social restriction occurred as time that could have been spent on social activities in the community was devoted to hours of study, usually in a role as an isolated learner. The promise of distance and online education for individuals who are residents in relatively isolated areas, often leads to their finding themselves increasingly socially isolated, as their education endeavours are primarily a solitary experience. Nonetheless, contributors who were aware of "Skills for All" were enthusiastic about the opportunities the program gave to individuals who were in receipt of low incomes. Furthermore, contributors expressed concerns about how funding cuts to the program would diminish opportunities for marginalised individuals to engage with education. However, adult learners did report some beneficial social experiences and their preference to engage with social activities that are organised within their geographic community. Encouragingly, some adult learners reported taking up opportunities to engage with individuals located in other geographic and spiritual communities. However, without the time for regular connection, these social opportunities did not form lasting relationships.

Some adult learners reported that since their engagement with education, they experienced significant personal benefits, including a sense of accomplishment and confidence in their abilities. However, this was often counterbalanced by disappointment with the outcomes from their social interactions in their geographic communities. This disappointment was framed in terms of contributors recognising that whilst change is not immediate they did expect to see signs of improvement in their community because of their efforts. In contrast to this expectation, contributors reported that their community groups often appeared stagnant, unappreciative of the efforts or disrespectful of some members, and did not seem to generate improvement in the community. The improvement, if any, did not appear to move at a pace that satisfied the efforts of the contributors. The social experiences of contributors that were generated by engaging with education were therefore mixed. Whilst new ideas may be generated in communities by adult learners, their novel solutions to existing problems or renewed social vigour seemed out of step with community practices. A foray into education that renews the perspective of the individual and fuels a difference in thinking through exposure to new ideas is not always welcomed by rural community culture.

\section{Summary}

This study examines an approach to finding the social experiences that facilitate social inclusion, particularly the process of becoming socially included in rural communities. Previous research on rural communities suggests that heightened social interactions are imperative if communities are to survive. Particularly, social interactions that include individuals who may be considered outsiders. Education, specifically the "Skills for All" program offers a personal opportunity for individuals residing in rural communities to study and bolster their social prospects. The case study method that utilised semistructured interviews reveals that the circumstances of education provision for adult 
learners in rural communities often isolate them from social purpose within their communities. This circumstance occurs despite often-renewed opportunities for learners to make social connections in either geographical or ideological communities. Coupled with their physical isolation as adult learners in rural communities, individuals often find themselves philosophically isolated as their education offers knowledge and links to alternate approaches to social conventions in their community.

In revealing the findings about social inclusion, the boundaries of communities and the influence of education on social experiences, contributors have been able to discuss and reflect on their experiences. The discussion and reflection that has occurred throughout this study has often facilitated contributor self-revelation about social processes and practices that further their life chances. This approach is mindful of the potential to generate greater marginalisation and contributors have not conveyed that they have experienced this through their engagement with this study. However, they have also reported that their education experiences and "Skills for All" do not necessarily lead to being "socially included" in a way that is either desirable for them or their community. Policy literature documents resources and capabilities as an important cornerstone of social inclusion; this study appreciates the nature of those resources and capabilities as a position whereby membership of a group may be used to assist others. This research also highlights the structures and processes of community and society that restrict or enable the potential of individual resources and capabilities within a marginalised social setting: namely, the rural communities of South Australia. If education is to assist the future of rural communities and their inhabitants then further research is needed from an aspect that seeks to understand the ways in which education can sustain the social priorities of rural communities.

\section{Works Cited}

Alston, M. (2004). 'You don't want to be a Check-out Chick all Your Life': The Out-migration of Young People from Australia's Small Rural Towns. Australian Journal of Social Issues, 39(3), 299-366.

Ashwood, L. (2010). Without Categories and Classifications: 'Rural' as a Social Expression. Research in Rural Sociology and Development, 16, 113-125.

Australian Social Inclusion Board. (2008a). Principles for Social Inclusion: Everyone's Job. Canberra, Australia: Social Inclusion Group.

Australian Social Inclusion Board. (2008b). Social Inclusion: Origins, Concepts and Key Themes. Canberra, Australia: Australian Government.

Australian Social Inclusion Board. (2011). Foundations for a Stronger, Fairer Australia. Canberra, Australia: Department of Prime Minister and Cabinet.

Government of South Australia. (2012a). Skills for All: Regional Analysis. Adelaide, Australia: Government of South Australia.

Government of South Australia. (2012b). Skills for All: Summary Report. Adelaide, Australia: Government of South Australia.

Gray, I., \& Lawrence, G. (2001). A Future for Regional Australia: Escaping Global Misfortune. North Ryde, Australia: Cambridge University Press.

Lenoir, R. (1974). Les Exclus: Un Francais sur Dix. Paris, France: Editions du Seuil.

Newman, L., Biedrzycki, K., Patterson, J., \& Baum, F. (2007). A Rapid Appraisal Case Study of South Australia's Social Inclusion Initiative A report prepared for the Social Exclusion Knowledge Network of the Commission on Social Determinants of Health (established by the World Health Organisation). Adelaide, Australia: Social Inclusion Unit. 
Onyx, J., \& Bullen, P. (2000). Measuring Social Capital in Five Communities. The Journal of Applied Behavioral Science, 36(1), 23-42.

Otero, G. (2012). Rural Communities... Education for the 21st Century Sidney Myer Lecture. Mount Gamber, South Australia: Flinders University.

Pritchard, B. (2005). Unpacking the Neoliberal Approach to Regional Policy: a Close Reading of John Freebairn's ‘Economic Policy for Rural and Regional Australia’. Geographical Research, 43(1), 103-112.

Smailes, P. J. (1995). The Enigma of Social Sustainability in Rural Australia. Australian Geographer, 26(2), 140-150.

Smailes, P. J. (2002). From Rural Dilution to Multifunctional Countryside: Some Pointers to the Future from South Australia. Australian Geographer, 33(1), 79-95.

Strega, S. (2005). The View from the Poststructural Margins: Epistemology and Methodology Reconsidered. In L. Brown \& S. Strega (Eds.), Research as resistance (pp. 199-236). Toronto, Canada: Canadian Scholars' Press.

Vinson, T. (2009). The Origins, Meaning, Definition and Economic Implications of the Concept of Social Inclusion/Exclusion. Canberra, Australia: Australian Social Inclusion Board.

Yin, R. (2009). Case Study Research: Design and Methods (4th ed.). California, USA: SAGE Publications, Inc. 